УДК 622.817 (571.17)

ВОПРОСЫ ПРЕДУПРЕЖДЕНИЯ АВАРИЙ, СВЯЗАННЫХ СО ВЗРЫВАМИ

METAНА В УГОЛЬНЫХ ШАХТАХ

${ }^{1}$ Минеев C.П.

${ }^{1}$ Институт геотехнической механики им. Н.С. Полякова НАН Украинь

\author{
ПИТАННЯ ПОПЕРЕДЖЕННЯ АВАРІЙ, ПОВ'ЯЗАНИХ З ВИБУХАМИ \\ METАНУ У ВУГІЛЬНИХ ШАХТАХ \\ ${ }^{1}$ Мiнеєе С.П.
}

${ }^{1}$ Інститут геотехнічної механіки ім. М.С. Полякова НАН Украӥни

\title{
ON THE ISSUE OF PREVENTION OF ACCIDENTS CAUSED BY METHANE EXPLOSIONS IN COAL MINES \\ ${ }^{1}$ Mineev S.P. \\ ${ }^{1}$ Institute of Geotechnical Mechanics named by N. Polyakov of National Academy of Science of
} Ukraine

Аннотация. Рассмотрены основные вопросы предупреждения шахтных аварий, которые связаны со взрывами метановоздушных смесей при ведении горных работ. Рассмотрена сущность вопроса повышенной взрыво-, газо- и пылеопасности при ведении горных работ в условиях шахт. В данной статье проведён анализ взрывоаварийности на шахтах и рассмотрены основные причины, приводящие к взрыву в шахте. Рассматривая эти основные причины и факторы, выделены следующие: нарушение режима проветривания из-за перераспределения воздуха между выработками; изменения режима работы добычных машин и организации работ в сторону ускорения, а также существенные изменения горно-геологических условий. При вскрытии забоем выработки геологического нарушения, зоны разгрузки пласта, устьев дегазационных, разведочных и других технических скважин без принятия соответствующих мер по улучшению проветривания достаточно часто имеют место загазирования, причём нередко импульсного характера.

Считается, что взрывы метана и угольной пыли являются одной из самых опасных подземных аварий. Аварии, связанные с воспламенениями метана в зависимости от характера протекания явлений и вызываемых последствий, условно разделяются на три группы: взрывы, вспышки и горение. Застигнутые аварией в шахте люди подвергаются угрозе поражения взрывной волной и отравления ядовитыми продуктами взрыва, возможны также тяжёлые последствия от недостатка в воздухе кислорода.

К основным факторам, стимулирующим реализацию взрывов метана, также относятся внезапные выбросы угля и газа, суфляяные и импульсные выделения метана. Кроме того, к причинам взрывов можно отнести неправильное разгазирование ранее заперемыченных выработок при изоляции пожаро- или взрывоопасного участка, плановые остановки главных и вспомогательных вентиляторов в результате ревизии, ремонта, демонтажа и переноса оборудования, реверса воздушной струи, инженерные ошибки в расчётах, замерах воздуха, применение несовершенных схем вскрытия, подготовки и отработки пластов, систем разработки, неудовлетворительный контроль за проветриванием горных выработок, а также не корректно работающая газоизмерительная аппаратура и другие фракторы.

Выполнен анализ причин и фракторов скопления метана, классификация их в отдельные группы, показана их многообразие, обращено внимание на сочетание неблагоприятных факторов, недооценку пылегазовой обстановки в процессе ведения горных работ.

Ключевые слова: авария, взрывы метана, пожар, аэрогазовый контроль, угольная шахта.

Общие сведения. Сущность вопроса повышенной взрыво-, газо- и пылеопасности при ведении горных работ в условиях шахт. Считается, что взрывы метана и угольной пыли являются одной из самых опасных подземных аварий. Застигнутые аварией в шахте люди подвергаются угрозе поражения взрывной волной и отравления ядовитыми продуктами взрыва, возможны также тяжёлые последствия от недостатка в воздухе кислорода. 
На угольных шахтах СНГ, в основном России, Украины и Казахстана ежегодно происходят десятки вспышек и взрывов метана. Наибольший резонанс в обществе вызывают взрывы метана с последующим подключением к ним угольной пыли и последующего возгорания пожара. Они, как правило, приводят к более катастрофическим последствиям для шахтёров и вызывают серьёзные, а иногда и невосстановимые разрушения на предприятиях. К таким авариям можно отнести аварии, произошедшие на шахтах Украины: им. К. Маркса (г. Енакиево), им. А.Ф. Засядько (г. Донецк), «Суходольская-Восточная» (г. Краснодон), «Краснолиманская», «ШУ Покровское», «Степова» и другие. Не менее серьёзные аварии, связанные со взрывами метана или метана и угольной пыли, происходят на шахтах России, Казахстана и других угледобывающих стран. Известны случаи, когда авария распространяется до поверхности с разрушением надшахтного здания, например авария на шахте им. К. Маркса (г. Енакиево). Социальное звучание каждой отдельной катастрофы достигает весьма значительных масштабов $[1,2]$.

Как считается, аварии, связанные с воспламенениями метана в зависимости от характера протекания явлений и вызываемых последствий, условно разделяются на три группы: взрывы, вспышки и горение [3, 4].

Взрыв - это быстрое сгорание метановоздушной смеси, сопровождающееся выделением большого количества энергии и образованием сжатых газов, способных производить работу. Для взрыва характерно образование ударной воздушной волны, которая может вызвать разрушение или повреждение горных выработок, сооружений, оборудования и механические травмы людей.

Вспышка - быстрое сгорание сравнительно небольшого объёма метановоздушной смеси без образования сжатых газов и динамического воздействия на окружающую среду. Чёткую границу между «слабым» взрывом и вспышкой провести нельзя. Условно можно относить к взрывам воспламенения, при которых избыточное давление воздуха превышает 0,01 МПа (безопасный для человека предел). Ещё большая неопределённость возникает при разделении вспышек и горения метана. Поэтому при анализе к группе «вспышки» отнесены как собственно вспышки, так и случаи более или менее длительного горения метана, в частности, эндогенные пожары, при которых материалом первичного воспламенения был метан.

Учитывая мощность источника и объёма взорвавшегося метана и угольной пыли взрывы условно разделяют на три типа [4]:

a) слабые взрывы, которые происходят при незначительном местном скоплении метана. При них срываются вентиляционные трубы, выбивается только, что поставленная крепь, рабочие получают ожоги и отравления средней и лёгкой степени;

б) взрывы средней мощности, которые возникают при наличии в выработках значительных объёмов метана в куполах и слоевых скоплениях. Такие взрывы разрушают сланцевые заслоны, крепление, находящиеся в забое люди часто погибают или получают тяжёлые ожоги и отравления;

в) взрывы большой мощности, которые, как правило, возникают при взрыве метана и затем угольной пыли. 
К поражающим факторам взрыва относятся фронт пламени, ударная волна и изменения состава шахтной атмосферы, т.е. тепловое, динамическое и токсическое воздействие [4].

Тепловое воздействие зависит от температуры пламени, продуктов взрыва и существенно - от времени его действия, т.е. скорости пламени. Обычно температура взрыва о неограниченном объёме по данным [4] достигает $1875^{\circ} \mathrm{C}$, а в закрытом объёме $1650-2150{ }^{\circ} \mathrm{C}$; температура пламени $2000-2150{ }^{\circ} \mathrm{C}$.

Сущность динамического воздействия заключается в том, что давление на фронте ударной волны при взрывном горении пылеметановых смесей составляет 0,8-1 МПа, достигая до 1,6 МПа. При таких давлениях действие взрыва достаточно велико, к примеру, при давлении 0,1 и более МПа степень травм шахтёров крайне тяжёлая и возможен смертельный исход.

Токсическое воздействие, как правило, выражается в отравлении окисью углерода $(\mathrm{CO})$ и уменьшенном количеством кислорода $\left(\mathrm{O}_{2}\right)$. При концентрации СО $1 \%$ человек после нескольких вздохов теряет сознание, а через 1-2 мин настаёт смерть. Обычно при концентрации $\mathrm{O}_{2} \quad 6-10 \%$ проявляется тяжёлая отдышка, слабость и потеря сознания.

При рассмотрении заявленного вопроса необходимо иметь в виду, что ежегодно на шахтах Украины возникало до десятка, а иногда более экзогенных пожаров и несколько эндогенных, что составляет около $60 \%$ всех аварий [5]. Рас-

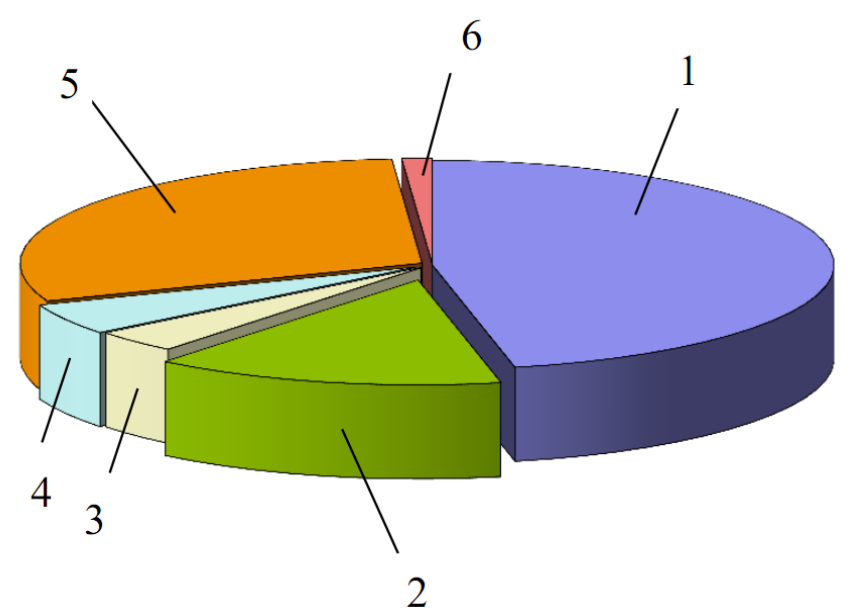

Рисунок 1 - Распределение по видам подземных аварий на угольных шахтах Украины (1991 - 2013гг): 1 экзогенные пожары (45,7\%); 2 - эндогенные пожары $(13,6 \%) ; 3$ - взрывы $(4,1 \%) ; 4$ - выбросы $(4,8 \%) ; 5$ обрушения (30\%); 6 - затопления $(1,2 \%)$ пределение подземных аварий на угольных шахтах Украины по видам представлено на рис. 1.

А рассматривая наиболее корректную статистику подобных аварий, собранную в МакНИИ [3] за 30 лет (1971 - 2000 гг.) в угольных шахтах Украины можно отметить, что произошло 92 взрыва и 297 случаев вспышек и горения метана. 91 взрыв метановоздушной смеси, в том числе 16 с участием угольной пыли, один пылевой взрыв и зарегистрировано 297 случаев вспышек и горения метана. Рассматривая эту статистику по взрывам метановоздушной смеси в шахтах следует отметить, что: по месту возникновения взрывы распределяются следующим образом: тупиковые выработки - 36 (39,1 \%); выемочные участки - 31 (33,7 \%); стволы, шурфы - 5 (5,4 \%); надбункерные камеры - 2 (2,2 \%); отработанные изолированные выемочные участки и выработки - 2 (2,2 \%); прочие выработки - $16(17,4 \%)$. 
По поводу участия угольной пыли во взрывах отметим следующее. Так, из 33 взрывов метана в тупиковых выработках на пластах, опасных по взрывам пыли, в 11, т.е. в каждом третьем участвовала угольная пыль. На выемочных участках при 25 взрывах на опасных по пыли пластах пыль участвовала в четыpëx.

К основным причинам образования опасной газовой среды при взрывах отнесено [3]: нарушения проветривания - 37 (37,4 \%); местное скопление метана - 16 (16,2 \%); повышенное статическое или импульсное газовыделение - 15 (15,2\%); накопление метана в выработанных пространствах - 10 (10,1\%); разгазирование тупиковых выработок и выемочных участков - 7 (7,1 \%); недостаточный расход воздуха - 5 (5,0\%); отсутствие проветривания - 4 (4,0\%); прочие - 5 (5,0 \%) (см. рис. 2).

Как видно из анализа статистики МакНИИ [3], основными причинами образования опасной среды, на которые приходится две третьих всех взрывов, являются нарушения проветривания, местные скопления метана и повышенное газовыделение. Первое место занимают нарушения проветривания. $\mathrm{K}$ местным скоплениям при анализе отнесены случаи образования в выработках местных скоплений при отсутствии каких-либо отказов систем общешахтного или местного проветривания. Существенной причиной повышенного газовыделения в рассмотренных случаях были выбросы угля (породы) и газа при сотрясательном взрывании, когда и следовало ожидать повышения газовыделения. При этом, вполне очевидно, что имеет место неизбежное для газовых шахт накопление в выработанных пространствах метана в опасных концентрациях.

По данным МакНИИ распределение числа взрывов по источникам зажигания характеризуется следующими данными: электрооборудование с питанием от сети и кабели - 33 (35,9 \%); взрывные работы - 18 (19,6 \%); пожары от самовозгорания и другим причинам - 10 (10,9\%); аккумуляторные электровозы - 9 
(9,8 \%); фрикционное искрение - 7 (7,6 \%); огневые работы - 6 (6,5 \%); нагревание вследствие искрения поверхности оборудования - 2 (2,1\%); по другим причинам и точно не установленные - 7 (7,6 \%) (см. рис. 3 ).

Вполне понятно, что данные о вспышках (горении) метана являются неполными. Так как аварии, не повлёкшие за собой травмирование людей, не всегда должным образом расследуются и регистрируются. Поэтому из зафиксированных 297 случаев вспышек (горения) 141 (41,5\%) относится к выемочным участкам. 104 (35,0 \%) - к тупиковым выработкам и 52 (17,5 \%) - к прочим выработкам. Основными причинами образования опасной газовой среды при этих авариях являются нарушения проветривания и местные скопления метана, а источниками зажигания - фрикционные искрения (35\%), взрывные работы $(34,7 \%)$, электрооборудование и кабели $(14,8 \%)$, самовозгорание и пожары по другим причинам (4 \%), огневые работы (3,4 \%), курение (1,3\%). Вспышки, вызванные другими и не установленными причинами, составляют 6,8 \%.

Таким образом, анализ статистики МакНИИ по взрывам метана показывает, что наиболее взрывоопасными объектами шахт являются выемочные участки и тупиковые выработки на которые пришлось 72,8 \% взрывов и 82,5 \% вспышек (горения) метана. Большая часть $(64,7 \%)$ взрывов с участием угольной пыли произошла в тупиковых выработках. Причём, основными причинами опасной газовой среды при взрывах являются нарушения проветривания $(37,4 \%)$, местные скопления метана $(16,2 \%)$ и повышенное статическое или импульсное газовыделение $(15,2 \%)$.

Как известно, для создания аварийной ситуации необходимым условием является образование взрывоопасной смеси и источников её воспламенения. Поэтому общеизвестно, что для предупреждения взрывов и вспышек в угольных шахтах необходимо выполнять одновременные мероприятия по трём направлениям: исключение возможности образования взрывчатых сред; применение шахтных технологий исключающих возникновение источников воспламенения взрывоопасной смеси, а также применения специальных систем предупреждения взрывов. Т.е. вроде все продумано.

Вместе с этим, слушая сообщения о взрывах и погибших у людей возникает вопрос: почему? У специалистов же возникает и другой вопрос: а что необходимо сделать, предпринять, что рекомендовать по предупреждению подобной аварии, или же может просто опустить руки - мол, это «Шубин», т.е. это просто наша расплата за нарушение целостности углесодержащих недр $[1,6]$. Данная проблема не нова, ею занимались многие десятки высококлассных специалистов и учёных, предложено много достаточно эффективных мер по предотвращению подобных аварий [1- 25 и др.]. Однако окончательного решения этой проблемы нет и самое обидное, что его не видно. Поскольку до конца не изучен механизм метановыделения в выработки, его статический и импульсный характер, всевозможных причин появления источника воспламенения, да и всевозможных вариантов и параметров углепородного массива существенно влияющих на эти факторы в различных горно-геологических условиях угольного предприятия. Поэтому каждое новое расследование и рассмотрение данной проблемы или её ана- 
лиз, по моему мнению, серьёзно приближает нас к её возможному решению. Поэтому автор данной статьи и попробовал провести свой анализ проблемы с учётом известных ему выполненных ранее результатов.

Общеизвестно, что наиболее эффективным средством борьбы с загазированием горных выработок метаном является вентиляция. Воздуха в шахту должно подаваться столько, чтобы содержание метана в атмосфере выработок не превышало пределов, установленных Правилами безопасности норм.

Однако, на большинстве шахт, одной вентиляцией невозможно обеспечить безопасную и высокопроизводительную выемку угля. Для таких условий применяется дегазация и другие меры. Кроме того, необходимо учитывать, что при высоких скоростях выемки угольных столбов нередко образовываются неожидаемые местные и слоевые скопления метана опасной концентрации, за счёт суфлярных выделений, обрушений основной пород кровли и других загазирований импульсного и статического характера.

Взрывоаварийность на шахтах. Рассмотрение характерных примеров последнего времени. Анализ основных причин, приведших к взрыву в шахте.

Рассматривая проблему взрывоаварийности, многие специалисты шутят: «Если есть метан - искра всегда найдётся». Однако на самом деле, все несколько сложнее, причин и факторов, оказывающих влияние на скопление - статические и импульсные загазирования и взрывы метана - несколько десятков. Это и главные, и сопутствующие, косвенные, и прочие. Рассмотрим эти основные причины и факторы.

1. Нарушение режима проветривания из-за перераспределения воздуха между выработками. В одном случае это происходит за счёт очередной сбойки двух или более подготовительных или выемочных выработок и отсутствия контрольного замера специалистами участка ВТБ за количественными изменениями подачи воздуха по забоям и выработкам, в первую очередь, наиболее удалённых от главных вентиляторов и трудно проветриваемых; в других - вследствие нарушения целостности вентиляционных сооружений при выполнении ремонтных, монтажных и других работ, в-третьих, это открытие вентиляционных дверей и перемычек (преднамеренное, вынужденное, непреднамеренное) рабочими при передвижении и транспортировке грузов. В настоящее время на угольных шахтах нет профессии дверовых, основные вентиляционные двери в околоствольных и главных выработках автоматизированы или имеют дистанционное управление с блокировкой для шлюзования. К сожалению, участковые вентиляционные двери не обслуживаются, многие не имеют дистанционного контроля их положения и блокировки при шлюзовании. Нередко данная причина может стать основным фактором, приводящим к загазированию выработок и, как следствие, к реализации аварии. В некоторых случаях установленные воздухо перераспределяющие перемычки, которые периодически то открывается, то закрывается, т.е. депрессия периодически изменяется, что является самым плохим фактором для устойчивости проветривания. Тоже самое имеет место при запуске новых лав практически всегда возникают новые воздушные потоки, существенно изменяющие депрессию, это в результате приводит к тому, что воздух нередко стремится идти по одному из новых потоков. 
При этом, как правило, расчёт устойчивости проветривания не выполняется или выполняется с некоторой задержкой. Здесь, следует отметить об аварии, произошедшей на шахте «Степова» ГП «Львовуголь» [5]. Одной из основных причин этой аварии на шахте «Степова», произошедшей 02.03.2017 года было как раз не управляемость перераспределением воздуха между выработками. Причём, этот взрыв и последующее горение метановоздушной смеси произошло при не работающем очистном забое.

По указанным причинам проветривание часто является не полностью управляемым, поэтому неплохо, когда на шахте имеется значительный резерв воздуха, за счёт которого частично покрываются такие потери. Тем не менее, необходимо также отметить, что низкая скорость движения воздуха приводит к недостаточной турбулентности воздушной струи, что способствует образованию слоевых скоплений метана повышенной концентрации, загазированию куполов, «кутков» и других участков. Согласно, выполненных исследований, около половины вспышек и взрывов метана в подготовительных выработках прямо или косвенно связано с наличием слоевых скоплений метана. Из-за недостаточной скорости струи воздуха возникают скопления метана высокой концентрации в местах воздействия исполнительных органов проходческих и добычных комбайнов на угольный массив. Такие ситуации нередко приводят к авариям, например, вспышки и загорания метана, имевшие место на ряде шахт Украины.

2. Изменения режима работы добычных машин и организации работ в сторону ускорения, непринятие при этом соответствующих мер по увеличению подаваемого в забой воздуха. На высокопроизводительных угольных шахтах такая причина, является достаточно распространённой для возможных загазирований и аварийности. Так, например, на шахтах можно встретить документацию, в которой расчёт количества воздуха, необходимого для проветривания очистного забоя, выполнен, исходя из средней нагрузки 1000 т/сут, а в конце или в средине месяца очистной забой 2-3 дня работает с интенсивностью 20003000 т/сут. Аналогичное несоответствие расчётных данных по проветриванию, фактическому режиму работы имеет место также и при скоростном проведении горных выработок проходческими комбайнами. При этом техслужба участков и шахты довольно часто не выполняет перерасчёт количества воздуха, необходимого для соблюдения требований Правил безопасности, а также и не увеличивают частоту уборки и увлажнения угольной пыли. К этой категории можно отнести взрывы метана и пыли на шахтах «Распадская», «Молодогвардейская» в России и им. Засядько и на других $[10,11]$.

3. Изменения горно-геологических условий. При вскрытии забоем выработки геологического нарушения, зоны разгрузки пласта, устьев дегазационных, разведочных и других технических скважин без принятия соответствующих мер по улучшению проветривания достаточно часто имеют место загазирования, причём нередко импульсного характера. Следует подчеркнуть, что изменение среды в горно-геологических нарушениях бывает не очень ярко выражено - в виде перемятого угля, появления пликативного нарушения и пр. При этом участок продолжает по инерции, выполнять необходимый цикл работ в забое по 
установившемуся ранее режиму и параметрам. Аналогичную позицию по отношению к параметрам и организации работ во многих случаях занимает руководство участка. Хотя Природа как бы предупреждает людей, работающих в забое, прямыми или косвенными признаками об изменении горно-геологических условий и, соответственно, приближающейся возможной опасности. К таким признакам относятся изменение структуры и кливажа угля, крепости и устойчивости вмещающих пород, цвета угля, «потение» забоя и бортов выработки, увеличение притока воды, горного давления на крепь, потрескивание и шелушение забоя на пластах, опасных по внезапным выбросам угля и газа, и др. Главное для руководителей и рабочих: во-nервых, своевременно уловить эти предупреждения природы, порой даже по неярко выраженным проявлениям, во-вторых, расшифровать их, а при необходимости пригласить геолога, маркшейдера, выполнить исследования и замеры, произвести бурение разведочных скважин, в-третьих, на основании имеющейся информации, опыта и даже интуиции сделать прогноз условий впереди забоя; в-четвёртыx, в соответствии с прогнозом внести соответствующую коррекцию в параметры технологии, организации работ в забое и меры по безопасности труда.

Необходимо отметить, что даже достаточно опытные руководители не редко забывают, что проведение почти любой выработки - это всегда в определённой степени разведка пласта и вмещающих пород, так как более половины всех мелких геологических нарушений являются непрогнозируемыми и, к сожалению, вскрываются только при проходке выработок. Наблюдения и контроль за структурой и поведением пласта нужны не только геологу и маркшейдеру для нанесения на планы горных работ, а в первую очередь тем, кто работает в забое для повышения свой же безопасности.

Прогнозирование горно-геологических условий, возможных осложнений и принятия без перестраховки соответствующих мер по безопасности можно, без преувеличения, отнести к элементам горного искусства, которым должны владеть все высшие специалисты, осуществляющие надзор и контроль за ведением горных работ на шахтах. На самом деле в результате неудовлетворительного прогноза геологических нарушений и имели место загазирования на многих шахтах, причём нередко, что более опасно, загазирования импульсного характера, приведшие к авариям на шахтах «Золотое» ГП «Первомайскуголь» (24.09.93 г.), им. С.М. Кирова ГП «Макеевуголь» (7.05.01г.), «Суходольская-Восточная» (29.07.2011г.), «Краснолиманская» (26-27.10.2015г.) и других [1, 21].

4. Неудовлетворительное управление кровлей и проведение неплановых часто ненужных выработок с последующей их изоляцией без погашения. В этом случае скопление метана происходит в выработанном, но не обрушившемся пространстве очистных забоев. На некоторых шахтах недооценивают скрытые, неконтролируемые скопления метана в куполах, завале за механизированной крепью лавы, в изолированной, но не погашенной выработке, на основании того, что метан практически всегда есть в выработанном пространстве. Нельзя считать изоляцией тесовую или органную перемычку, например, в тупи- 
ковой части вентиляционного или конвейерного штреков лавы, и, тем более, профилактической мерой против попадания метана в действующие выработки участка.

Неудовлетворительная изоляция выработанного пространства, наличие пустот, больших утечек воздуха, особенно в зонах геологических нарушений, неоднократно являлись причинами самовозгорания угля и последующих взрывов метана с приостановкой горных работ на длительное время в целом по шахте. Такие аварии, в том числе с человеческими жертвами, имели место на многих шахтах.

5. Нарушение проветривания тупиковых забоев в результате остановки вентилятора местного проветривания, разрыва вентиляционных труб, пережатия и несвоевременного их наращивания в призабойном пространстве. Особое внимание при этом необходимо уделять низким скоростям движения воздуха по выработкам. Так, в результате недостаточной турбулентности воздушной струи образуются местные и слоевые скопления метана высокой концентрации, загазирование куполов, «кутков», тупиков и других слабо обдуваемых участков выработок (забоев). Согласно исследованиям, около половины вспышек и взрывов метана в подготовительных выработках прямо или косвенно связано с наличием местных и слоевых скоплений метана. Нередко из-за недостаточного проветривания (скорости струи воздуха) и отсутствия дегазации, а также при отсутствии орошения рабочего органа комбайна, возникает скопления метана высокой концентрации и в местах воздействия исполнительного органа проходческих и добычных комбайнов на угольный массив происходят искрения, которые в некоторых случаях приводящие к взрывам метана.

6. Внезапные выбросы угля и газа, суфлярные и импульсные выделения метана. На шахтах Донецкого, Кузнецкого и других бассейнов аналогичные загазирования выработок участка, крыла, горизонта неоднократно происходили при вскрытии пластов квершлагами, сотрясательном взрывании, когда все люди из шахты должны быть выведены и электроэнергия отключена. Из практики известны случаи взрывов метана во время или после внезапных выбросов, в том числе спровоцированных выбросов. Газодинамические явления могут привести к загазированиям, последующим взрывам метана и что ещё хуже - к взрывам пыли. Так, например, на шахте «Суходольская-Восточная» в выработке, проводимой взрывными работами в режиме сотрясательного взрывания, произошёл небольшой выброс, который сбил рукав вентиляционной трубы. После проветривания, люди, как обычно, пошли на осмотр забоя, увидев сбитую трубу восстановили её, за счёт которой затем была выдута незначительную часть метана из забоя. В это время электрослесарь начал ремонтировать пускатель, зона проветриваемого метана подошла к пускателю, слесарь все скрутил и как делал наверняка ранее десятки раз по телефону попросил быстренько проверить (зачем заранее мучиться и прикручивать крышку), что было исполнено, произошла вспышка метана, поднялась пыль и взорвалась - в результате все, кто находился до ствола (более 1 км.), а это более двух десятков человек, погибли. И если анализировать подобную аварию, то с первого взгляда - всё как всегда - классическое случайное стечение обстоятельств. А на самом деле-среди погибших более 
половины были люди с высшим образованием, которые знали Правила безопасности. В забой пошли люди, которые на месте уже знали, что будут из забоя выдувать газ, что электрослесарь должен ремонтировать электропускатель, причём вместе со слесарем был ещё и механик и т.д. Т.е. в результате ряда наших «авось пронесёт», опять стала серьёзная авария.

7. Неправильное разгазирование ранее заперемыченных выработок при изоляции пожаро- или взрывоопасного участка в результате быстрого вытеснения из него метана высокой концентрации в выработки.

При изоляции аварийного участка контроль его состояния осуществляется по концентрации индикаторных газов в выработанном пространстве и температуре, оцениваемой по непредельным углеводородам. По составу рудничного газа оценивают, что в изолированном пространстве процесс горения прекратился. Содержание оксида углерода в рудничной атмосфере изолированного пространства стабильно в течение 1-2 месяцев ниже допустимой нормы и фоновых значений. На основании изложенного принимается решение, что пожар может быть переведён в категорию потушенных и подлежит списанию с последующим выполнением работ по восстановлению нормального режима проветривания аварийного участка. Понятно, что перевод пожара в категорию потушенных, его списание, и вскрытие изолированного пространства производится в соответствии с требованиями «Правил безопасности в угольных шахтах».

Однако, в реальных условиях при выполнении работ по разгазированию заперемыченных ранее участков, нередко образовываются зоны скоплений метана повышенной концентрации, которые двигаясь по выработкам могут встретить очаги самовозгораний либо источники тления или не окончательно потушенного пожара. Это естественно приведёт к новой вспышке и т.д. по известному сценарию, что, к сожалению, происходило на ряде шахт.

8. Плановые остановки главных и вспомогательных вентиляторов в результате ревизии, ремонта, демонтажа и переноса оборудования, реверса воздушной струи. Аварии с вентиляторами, электрооборудованием и электрическими сетями. Однако из-за изменения депрессии, перераспределения воздуха между выработками и аэродинамической связи их с отработанным пространством происходили подсосы воздуха, непригодного для дыхания, что приводит к групповым несчастным случаям. Кроме того, неудовлетворительное состояние главных вентиляторов, вентиляционной сети, из-за нарушений схем вскрытия, недостаточного сечения выработок часто приводит к громадным внешним и внутренним потерям воздуха и не позволяет увеличить количество подаваемого в шахту воздуха. Чаще всего, в этом случае, расчёты необходимого количества воздуха и «правильно» подгоняются за счёт различных коэффициентов к максимально возможной величине. Это относится к так называемой категории шахт с неудовлетворительным проветриванием, вследствие недостаточной производительности вентиляторов. На некоторых шахтах до их ликвидации производительность главных вентиляторов составляла, пусть 25-40 тыс.м ${ }^{3} /$ мин., а подавалось в шахту 15 тыс.м ${ }^{3} /$ мин, при потребности $18-20$ тыс. $^{3} /$ мин.

9. Инженерные ошибки в расчётах или замерах воздуха, в том числе при работе главных вентиляторов в различных режимах или без них, приводящие 
к неверной оценке максимально допустимого развития горных работ: темпам выемки угля, проходке выработок и пр. Это, в свою очередь, может привести к загазированию забоя и последующему взрыву. Поэтому вполне очевидна необходимость разработки нормативного документа по определению максимально допустимой нагрузки на очистной забой по газовому фактору с учётом фактического метановыделения и достигнутой эффективности дегазации. Также при ошибках в расчётах, соответственно, используются неправильно выбранные режимы проветривания при ликвидации аварий, обрушениях и завалах (наиболее часто при пожарах), в том числе согласно плана ликвидации аварий, которые могут привести уже к повторным взрывам.

10. Применение несовершенных схем вскрытия, подготовки и отработки пластов, систем разработки, приводят к образованию местных скоплений метана в «кутках» очистных забоев, нишах, тупиках у перемычек при возвратноточном проветривании. Причём эти местные скопления часто невозможно проконтролировать системой АГК. Работающие в шахте нередко пренебрегают и тем фактом, что скоплению взрывчатой концентрации метана в отдельных выработках способствует, кроме прочего, тепловая депрессия, в том числе возникающая при пожарах.

11. Неудовлетворительный контроль за проветриванием горных выработок. При оснащении шахт системой АГК, на многих шахтах существенно был сокращён штат ВТБ и теперь даже раз в сутки не всегда обеспечивается оперативный контроль службой вентиляции и техники безопасности за концентрацией метана в выработках и местах, где нет датчиков АГК. Кроме того, следует иметь в виду, что используемые системы АГК на шахтах имеют недостатки, приводящие к аварийным ситуациям, которые условно можно разбить на две группы. Первая групnа, ошибки при разработке проекта АГК, включающие в себя: неверную расстановку датчиков и увязку их с отключаемом оборудованием, а также недостаточный учёт всех горно-геологических факторов шахты при разработке проекта АГК. Вторая групnа, это уже ошибки при эксплуатации системы АГК, т.е. получение недостоверных данных от датчиков контроля. Основные причины получения не соответствующих действительности данных от датчиков АГК в основном следующие: проблема с электропитанием; перенос датчиков; неверная настройка и расположение датчиков контроля; потеря связи с сервером; нестабильность системы проветривания; ремонтные операции с системой контроля; отсутствие датчиков скорости воздуха в местах размещения датчиков контроля метана), сбои программного обеспечения работы компьютерного комплекса, технические неисправности аппаратуры, а также ошибки, т.е. человеческий фактор.

12. Не корректно работающая газоизмерительная аппаратура. В последнее время, в силу ряда причин, некоторые элементы газоизмерительной аппаратуры не всегда тарируются и продлеваются сроки их корректной эксплуатации в установленном требованиями ПБ порядке и в необходимые сроки. Например, при работе системы УТАС, выполняющую на шахте роль информационного канала или как управляющая система, не всегда осуществляется ежесменный 
контроль - проверку работы датчиков системы. Все это может привести к недостаточно точному измерению и далее возможных загазирований и т.д.

\section{3. Недостаточно правильный учёт влияния БВР на аэрогазовое состо-}

яние массива. На шахтах, как известно, имеет место в процессе и после выполнения взрывных работ интенсивное выделение метана из отбитой горной массы, обнажённого массива, груди забоя и боков выработки, а также взрывом нередко вскрываются суфлярные выделения газа. Как правило, в таких случаях рекомендуется через 3-5 минут после взрывных работ производить замеры концентрации метана и оценивать возможные кратковременные или длительные загазирования с помощью специальной газоизмерительной аппаратуры. При загазированиях забоя выработки и нарушении требований ПБ при взрывных работах неоднократно происходили загорания, вспышки и взрывы метана от высокотемпературных продуктов взрыва или выгорания ВВ.

При отработке выбросоопасных угольных пластов в процессе производства взрывных работ в режиме сотрясательного взрывания, довольно часто происходят различные газодинамические явления, в результате которых нередко имеют место аварии с человеческими жертвами. В некоторых случаях такие аварии являются первопричиной дальнейшего их развития в виде последующих взрывов и иногда пожаров [24, 25].

\section{4. Недостаточное внимание уделяемое сопряжению лав с вентиляци-} онными выработками. Проведённые газовоздушные съёмки на 60 выемочных участках шахт Донбасса при прямо - и возвратноточных схемах проветривания с подсвежением исходящей струи (схемы типа 2-В и 3-В) и при возвратноточных с погашением выработок (схемы типа 1-М) показали, что абсолютная метанообильность участков изменялась от 1,5 до $35 \mathrm{~m}^{3} /$ мин. Установлено, что даже при наиболее надёжных схемах (с подсвежением исходящей струи со стороны целика угля) опасные местные скопления метана могут возникать у верхних бутовых полос и в вентиляционной выработке на некотором расстоянии от очистного забоя. В лаве такие скопления метана образуются, когда со стороны выработанного пространства у вентиляционной выработки устраивается плотная изоляция: бутовая полоса шириной более 5 м или с герметизирующей стенкой (покрытием). При этом, метан с утечками воздуха поступает из выработанного пространства в рабочее, образуя в нем местные слоевые скопления с взрывоопасными концентрациями. Длина таких скоплений может достигать 50 м, а толщина при концентрации метана не менее 5 \% в основном не превышает 20 см. Местные скопления формируются на участках выработок в 20- 100 м от лавы, где более высокое содержание метана в утечках воздуха через выработанное пространство [23].

При схемах проветривания с подсвежением исходящей струи со стороны выработанного пространства (схема типа 2-M) на сопряжении лавы с вентиляционной выработкой в лаве на протяжении 5-20 м практически всегда формируются опасные местные скопления метана за исключением участков с низкой газообильностью (до $1,5 \mathrm{~m}^{3} /$ мин).

Основными условиями безопасного применения прямоточных схем проветривания выемочных участков с подсвежением исходящей струи со стороны 
целика угля являются: средняя скорость движения воздуха в вентиляционной выработке более $1 \mathrm{~m} / \mathrm{c}$; применение для поддержания вентиляционной выработки неплотных устройств (костров, бутокостров, бутовых полос с каналами).

Схемы проветривания выемочных участков с подсвежением исходящей струи воздуха со стороны выработанного пространства в газовых шахтах можно использовать в исключительных случаях - при газообильности выработанного пространства не более 1,5 м³/мин. При схемах проветривания с погашением вентиляционных выработок в большинстве случаев следует применять дополнительные меры борьбы с газом на сопряжении очистного забоя с вентиляционным штреком. К сожалению, на некоторых шахтах в проектах проветривания выемочных участков, схемы не проверяются по опасности образования местных скоплений метана, что приводит к повышенной опасности реализации аварии.

15. Недостаточное внимание, уделяемое устойчивости вентиляционной выработки. На самом деле, за счёт потери устойчивости выработок (пучение, зажатие, обрушение пород и пр.), как правило, уменьшается их сечение, которое приводит к уменьшению количества воздуха, проходящего через них и, соответственно, очистной забой. Нередко, это приводит особенно на участке сопряжения очистного забоя с вентиляционным штреком к существенному уменьшению скорости воздуха, что способствует образованию местных и слоевых скоплений метана. Причём, необходимо отметить, что иногда даже незначительное скопление метана (объёмом менее $1 \mathrm{~m}^{3}$ ) при возгорании и вспышке приводит к достаточно серьёзным авариям. Такие аварии произошли в последнее время на шахтах «Степова» (02.03.17), «Новодонецкая» (12.06.17) и других.

16. Неверный выбор места размещения участкового электрооборудования. В некоторых случаях, на шахтах, особенно отрабатывающих пологие пласты, на вентиляционном штреке устанавливается электрооборудование, иногда в нем обустраивается и скребковый конвейер, т.е. вентштрек фактически начинает выполнять роль, как бы «конвейерного» штрека. В подобном случае исходящая струя нередко с повышенными концентрациями метана попадает на участковое электрооборудование, которое не всегда, к сожалению, имеет исключительную взрывозащиту.

\section{7. Недостаточное внимание, уделяемое содержанию метана и индика- торных газов для дорабатываемых лав.}

При ведении горных работ в высокопроизводительных лавах, особенно после длительной остановки забоя по разным причинам, например, после аварий в этой лаве или на соседних участках, фоновые концентрации индикаторных газов не всегда корректно оцениваются по длине очистного забоя и во времени. Нередко, особенно при доработке лав, начинает периодически изменяться показатели СО и другие. Эти изменения не позволяют однозначно констатировать процессы, происходящие в углепородном массиве. Это может быть горение, а может увеличение СО дать и гниение. Поэтому, в дальнейшем при доработке конкретной лавы может реализовываться как негативный, так и позитивный сценарии развития событий. Учитывая это, необходимо при доработке лавы надеясь на позитивный сценарий развития событий в лаве, быть готовым к развитию негативного сценария, т.е. начало возгорания. Для этого необходимо выполнить ряд мер 
по подготовке к возможной быстрой изоляции рассматриваемого участка. Т.е. необходимо подготовить и согласовать в установленном порядке техдокументацию на случай возможной реализации аварии, вести постоянный мониторинг газовой ситуации и температуры, предварительно рассчитать и подготовить опасные места в выработках (возможного установления перемычек), продумать вопросы приобретения гипса и прочих материалов.

18. Недостаточная изученность закономерностей выделения газов в горные выработки. Источниками газовыделения в шахтах, как правило, являются вмещающие пласт породы, угольные пласты, работающее оборудование и взрывные работы. Две последние группы источников можно рассматривать как точечные, интенсивность которых определяется преимущественно техническими параметрами и не представляет собой сложности для описания и расчёта. Газоносные породы представляют собой распределенные источники с существенно изменяющейся во времени интенсивностью. Применительно к метану различают три вида выделения газа с обнажённых поверхностей: обыкновенное, суфлярное и импульсное (внезапное). Поэтому адекватное математическое описание этих процессов и установление корректных закономерностей метановыделения в выработки представляет собой весьма значительное научное и практическое значение с точки зрения повышения безопасности ведения горных работ.

Другим не менее серьёзным моментом для оценки возможного метановыделения в шахте является учёт влияния солнечной активности, приливных деформаций, фаз луны и других факторов космогенного характера. К сожалению, научная и производственная элита с некоторым предубеждением относится к подобным исследованиям и даже считают их как бы «антинаучными». В тоже время некоторые руководители негласно пользуются услугами различных магов и других «антинаучных» авторитетов для оценки технического состояния своего предприятия, в том числе техногенного. Если отбросить всякие предубеждения, то к настоящему времени выполнен целый комплекс исследований по возможности прогнозирования различных аэрогазовых проявлений, как динамического, так и статического характера. В частности, было изучено влияние приливных деформаций, солнечной и лунной активности на реализацию газодинамических явлений, причём авторами этих работ получена хорошая сходимость. Никто не обращает внимание на то, что на некоторых шахтах наибольшее число аварийных ситуаций происходит в определённый день недели. Поэтому, на мой взгляд, нельзя отметать новые-старые гипотезы и мнения до тех пор, пока не будет установлено обратное.

19. Не достаточный учёт влияния выработанного пространства на взрывоопасность в шахтах. Газовыделение из выработанных пространств имеет место в выработках, оконтуривающих зону обрушения. В выработанные пространства метан поступает из угольных пластов и пропластков, невынимаемых целиков и пачек, попадающих в зону обрушения, а также из сближенных пластов в разгруженной части массива - из подработанной и надработанной толщ пород. Фильтрация газа из выше- и нижележащих слоёв осуществляется под действием разности давлений газа в невынимаемых пластах и в выработан- 
ном пространстве. Оценка интенсивности газовыделения в выработанные пространства является наиболее сложной для её формализованного математического описания, так как процесс выделения метана в данном случае в значительной степени определяется утечками воздуха через обрушенные породы. Условия поступления метана в область фильтрационного потока утечек также достаточно сложны, и взаимодействие потока утечек с процессами десорбции метана из вмещающего массива при его разгрузке практически не изучено. Прогноз газовыделения затрудняется тем, что источники его многочисленны и различны как по интенсивности, так и по своей локализации в пространстве.

Установлено, что метановыделение из вмещающего массива в выработанные пространства тесно связано с процессами сдвижения пород в ходе очистной выемки. Наиболее интенсивно газоотдача происходит в зоне частичной разгрузки от горного давления, которая перемещается вслед за лавой. Так же перемещается и зона интенсивного проветривания обрушенных пород. Взаимоналожение этих зон приводит к определённому распределению метана в выработанном пространстве. Вблизи очистного забоя концентрации минимально низкие, по мере удаления в глубь выработанного пространства они возрастают, достигая максимума примерно на границе зоны интенсивного проветривания, и затем снижаются и стабилизируются на некотором уровне в зоне уплотнения обрушенных пород. Для ряда схем проветривания (с двусторонним примыканием выработок к выработанному пространству) положение зоны высоких концентраций зависит от интенсивности фильтрационных потоков. Тем не менее, решение таких задач может существенно повысить безопасность работ в шахтах.

20. Отсутствие в достаточной степени корректных методик и аппаратуры по оценке природной метаноносности угля и вмещающих пласты пород. Отсутствие таких методик не позволяет оценивать фактическую опасность при различных метановыделениях и возможности последующих загазирований выработок в реальных условиях ведения горных работ. Поэтому, вполне очевидна необходимость проведения более глубоких исследований по совершенствованию методик определения метаноносности горного массива, а также приложения серьёзных усилий, направленных на повышение надёжности проводимых исследований и совершенствование технического оснащения лабораторий. Такой комплексный подход к более серьёзному изучению газоносности, совершенствованию нормативных документов и оснащению технических лабораторий позволит более надёжно оценить фактическую метаноносность конкретного забоя, чем существенно повысить безопасность работ за счёт применения более эффективных рекомендаций.

Анализируя и обобщая причины скопления, загазирования, взрывов метана с позиции проветривания следует заметить, что каждая из причин имеют разновидности. Выделение причин и факторов скопления метана, классификация их в отдельные группы выполнены несколько условно, с тем, чтобы показать их многообразие, на конкретных примерах рассмотреть ту или иную особенность инкубационного периода скопления, загазирования и взрыва метана, обратить внимание на сочетание неблагоприятных факторов, недооценку пылегазовой обстановки в процессе работы. 
Загазирования выработок, в том числе местные скопления метана чаще всего производят не по одной, а двум, трём и большему числу перечисленных выше причин. При расследовании взрывов определяется основная причина скопления метана, а косвенные, но не менее существенные, упускаются. Более того, иногда причины скопления метана до взрывной концентрации не относят к разряду основных, так как все внимание при расследовании концентрируется на выявлении источника взрыва метана и угольной пыли. Это принципиально неверное направление и ошибочное мнение. Если в выработке имеется систематическое превышение концентрации метана сверх норм ПБ, источник воспламенения, как принято говорить, «всегда найдётся».

Большая половина перечисленных факторов и причин являются характерными для многих шахт, примерно половина из них присуща шахтам III категории и сверхкатегорийным, опасным по выделению и взрыву метана. Практически на каждой шахте имеется тенденция к ежегодному повышению газовыделения за счёт ряда факторов.

Одновременно с наличием аналогичных причин взрывов метана и катастроф есть десятки, сотни различных сочетаний и неблагополучных стечений обстоятельств как с выделением метана, так и проветриванием. То есть каждый взрыв - это результат того, что кто-то что-то неправильно оценил, спрогнозировал, принял ошибочное решение, неправильно действовал и т.д.

Обобщения, связанные с проявлением опасности метана, и основные направления и меры по снижению взрывоопасности шахт. Извлечение метана, дегазация угольных пластов и горного массива с поверхности в региональном масштабе месторождений для подготовки запасов угля к высокоэффективной и безопасной работе пока не всегда осуществляется. Подземный способ дегазации пластов, спутников их, горного массива применяется в недостаточных объёмах, чаще всего на тех шахтах (или пластах), где средствами вентиляции невозможно снизить содержание метана в горных выработках до норм, определённых ПБ, а не как профилактическая мера, повышающая безопасность, исключающая взрыв метана. Таким образом, метан, как и прежде, продолжает оставаться одним из самых опасных спутников шахтёров, особенно при проведении выработок и очистной выемки угля, создавая дополнительные трудности и экономические проблемы при разработке многих угольных месторождений. Основным направлением снижения взрывоопасности следует считать дегазацию в её классическом виде. В связи с интенсивностью горнопроходческих и очистных работ увеличивается количество выделенного метана из горного массива и отбитой горной массы. В отдельных, проводимых по углю выработках объём его достигает 1000-3000 м³ в сутки, а в очистных забоях в среднем 20-30 м на 1 т суточной добычи (на отдельных шахтах 100-150 м³). Этот фактор привёл к тому, что некоторые очистные и подготовительные забои работают на пределах возможности по проветриванию (наличию содержания метана на исходящих струях до 1$1,3 \%$ ), что не позволяет увеличить объём добычи и проходки за сутки.

На шахтах имеются явно выраженные удлинения и усложнения вентиляционных сетей. Связано это, в основном, с прекращением проходки стволов, от- 
ставанием проходки капитальных горных выработок, вскрытием запасов на низлежащих горизонтах по временным локальным схемам. Это приводит к увеличению протяжённости поддерживаемых выработок на 1000 т добычи угля, расходу электроэнергии на проветривание, росту внешних и внутренних потерь воздуха.

Сложность вентиляционных сетей, высокое сопротивление горных выработок, выборочная отработка «хлебных» пластов, проветривание требует на многих шахтах реконструкции вентиляции. Как горные выработки требуют ремонта, так и вентиляция периодически требует реконструкции и упорядочения её основных параметров. Иногда выделение метана происходит неравномерно. Зональное, внезапное и импульсное выделение при выбросах угля и газ, приурочено к периодическому обрушению основной кровли, геологическим нарушениям, в некоторых случаях трудно прогнозируемое и предсказуемое. Всякая внезапность увеличивает вероятность аварии. Из этого следует острая необходимость повысить достоверность горных и газовых условий.

\section{Почему же, несмотря на существующие комплексы мероприятий, про- исходят взрывы на шахтах?}

Что лежит в основе этих аварий? И главное, что делается в направлении сближения с мировым уровнем газовой безопасности угольных шахт?

Прежде всего, при анализе, как многими отмечалось, следует исключить удобную ссылку на снижение дисциплины труда. Начавшийся несколько ранее период «анархии» в угольной промышленности можно считать давно закончившимся.

Нельзя считать воспламенение метана и чистой случайностью. Точнее другая общеизвестная позиция: «Случайность - проявившая себя закономерность». Для видения развития рассматриваемой проблемы, понимания существующих законов и правильного отношения к ней в будущем, необходимо всё-таки попытаться акцентировать, что же всё-таки такое для нас шахтный метан.

Метан - друг и враг. Содержащийся в угольных пластах метан нельзя оценивать как свободный газ, т.к. он миллионы лет сохраняет своё состояние в составе углеметанового вещества, находясь достаточно близко к дневной поверхности при вполне значимой для этого периода времени проницаемости. Всем известно, что свободного газа в угле всего не более 10-15 \%, а остальной газ находится в связанном состоянии, это в основном сорбированный газ, а также может имеет место при определённых условиях в разном количестве гидратный, генерируемый в угле и др. виды. Аналогичная ситуация и в окрестностях горных выработок, когда за небольшой зоной газоистощения газодинамические характеристики пласта сохраняются десятки лет. Границу этой зоны принято называть поразному, например есть термин «газовый барьер». Природа его существования в полной мере ещё не изучена, хотя уже имеется ряд научно обоснованных гипотез [23].

В период разработки месторождения метан способен не только интенсивно выделяться, но и формировать процесс динамического саморазрушения пласта угля и даже прочного песчаника в виде внезапного выброса с интенсивностью десятки тонн угля и сотни кубометров метана в секунду. Максимальная масса 
выброса до 14000 т угля за три с половиной минуты и 350000 кубометров метана имела место на шахте им. Ю.А. Гагарина (г. Горловка).

Рассматривая особенности возникновения, развития и затухания различных видов газопроявлений, нужно отметить принципиально важный момент. Все они приурочены к зонам влияния технологического воздействия - чем оно интенсивнее, тем динамичнее возможная реакция горного массива. В тоже время, скорости выемки угля становятся столь велики, что существующие методы и средства оценки ситуаций приводят к запаздыванию управляющих решений и, соответственно, к снижению их эффективности. Технолог и проектировщик на шахте сталкиваются с типичной ситуацией «информационного барьера», характеризующейся тем, что сложность управляемой системы, количество причинноследственных связей по объёму информации намного превосходят возможности по её переработке отдельным человеком или группой специалистов. Выход может быть найден только на пути использования более современных автоматизированных систем с компьютерным управлением. Однако, все известные системы, в т.ч. с компьютерным оснащением, пока ограничены информационноконтролирующими функциями.

Из опыта известно, что любое сооружение и предприятие имеют вполне определённый срок эффективной эксплуатации. Однако он, по известным экономическим причинам, не всегда выполняется, и, как следствие, снижаются требования правил безопасности. Статистика показывает, что система газового контроля шахт раз в сутки сигнализирует о неблагополучном состоянии технологий подземной разработки. Считается, что до двух процентов загазирований перерастают в горение, вспышки и взрывы метановоздушной смеси.

«Человеческий фактор» является достаточно распространённой причиной наиболее серьёзных аварий на шахтах. Как правило, такие аварии произошли на шахтах, оснащённых современной высокопроизводительной угледобывающей техникой.

Почему? Например, каждый горный мастер в СССР перед сменой заполнял путёвку, на которой типографским способом было поперёк путёвки напечатано: «Безопасность труда - прежде всего». Ответ может быть один: законов много, все они суровые, но мы умеем их обходить и договариваться. Рабочий, видя, что процесс добычи ведёт к росту концентрации метана, не прекращает работу. Технический надзор не видят в этом непрофессионализма. Хотя, нередко и сам этот технадзор пропускает опасные и вполне заранее известные ему зоны возможного загазирования при ведении выемочных работ. Вышестоящий состав относится с некоторым «пониманием» к объективности ситуации - нельзя останавливать забои, а тем более шахту - жить будет не на что! И это тоже, к сожалению, верно.

С одной стороны, достаточно часто, искрой для взрыва или вспышки является наплевательское отношение к требованиям ПБ; к примеру, электрослесарь рассуждает примерно так: если я буду выполнять работу со всеми правилами, то я могу не выполнить наряд и опоздать на клеть, или уходить из забоя позже проходческой или добычной бригады, а может, и бежать к стволу, чтобы опять же успеть. Конечно, он сделает все не по правилам, так, как он или его коллеги делали, может, десятки и сотни раз. Например, проверить электросоединение, не 
закрутив все болты крышки пускателя, или чего другого. И тут на беду в этот момент почему-то образовалась повышенная концентрация метана. Случайное импульсное его выделение, частичная или полная посадка кровли, интенсивный перевод сорбированного газа в свободный - и можно перечислить ещё много разных причин. Так вот, примерно такие сценарии рассматриваются экспертными комиссиями неоднократно. Примерно так произошли аварии на «СуходольскойВосточной», «Краснолимаской» и во многих других случаях.

К сожалению, техническим руководством служб безопасности, не в достаточной степени используются сформулированные рядом учёных основы деятельности человека в экстремальных условиях. В отрасли серьёзно не учитывается неравномерность возрастного развития работника, выражающаяся в том, что отдельные психические функции и их личностные качества имеют определённую траекторию изменения во времени как по простому, так и достаточно сложному закону. Поэтому необходимо учитывать, что в сложных условиях величина отклонения от среднего значения психического состояния работника специфична для различных шахтёрских профессий.

При рассмотрении данного материала хотелось бы остановиться ещё на одном моменте, который непосредственно не имеет отношение к реализации аварии, но, по моему мнению, является весьма ответственным и достаточно серьёзным для шахтёров - это процесс расследования самой аварии. Понятно, что эксперты в процессе расследования аварии должны в конечном счёте дать ответы на основные вопросы: что произошло, почему произошло и как сделать что бы это не произошло в дальнейшем, т.е. выдать рекомендации. Также понятно, что в комиссию должны входить специалисты высшего уровня, понимающие и разбирающиеся в данной проблеме. Однако всегда существует и морально- этический уровень. Давать свои суждения по характеру расследования аварий, думаю, автор имеет моральное право, учитывая опыт участия в таких расследованиях, в том числе неоднократно, в роли председателя экспертной комиссии.

Так вот, всегда существует морально-этический уровень поведения членов экспертных комиссий при расследовании аварии и написания заключения по ней. Ведь нередко можно попытаться поднять свой рейтинг или свою значимость и «цену» за счёт дальнейшей судьбы технических руководителей шахты путём написания или шантажа написания каких-либо особых мнений, которые не всегда имеют прямое отношение к причинам данной аварии и, к сожалению, иногда некоторые эксперты бывают склонны к таким приёмам. Хотя хотелось бы, что бы эксперты искали новые технические возможности для предотвращения подобных аварий, а не делали акцент на поиск фактов, способствующих в дальнейшем более серьёзному наказанию виновных.

Подводя итог, хочется пожелать всем нам - от рабочего и учёного до руководителя и собственника шахт - прийти к пониманию материальной оправданности высокопрофессиональной работы, неизбежности изменения в ней личного, а не коллективного материального уровня при ошибочных решениях по безопасности на всех стадиях производства. Тогда, возможно, подобные вопросы будут не так актуальны. 
С другой стороны, в последнее время, принято считать, что практически все аварии, связанными со взрывами метана и угольной пыли происходят в основном из-за грубых нарушений Правил безопасности, т.е. человеческого фактора. К сожалению, так проще расследовать аварию, проще найти причину и виновника, которого накажут впоследствии. Хотя все мы понимаем, что в результате извлечения из недр огромных объёмов угля происходит существенного сдвижение подработанного и надработанного горного массива, что не может, при определённых горно-геологических условиях не сопровождаться непрогнозируемыми естественными природными явлениями, в том числе и ранее неизвестными.

\section{СПИСОК ЛИТЕРАТУРЫ}

1. Минеев, С.П. Враг или друг шахтный метан? Это решают люди / С.П. Минеев // Охорона праці: Додаток до журналу. Київ. - 2017. - № 12. - С. 49- 53.

2. Минеев, С.П. О предупреждении аварий, связанных со взрывами метана в угольных шахтах / С.П. Минеев // Уголь Украины. - Київ. - 2018. - № 1-2. - С. 50-59.

3. Брюханов, А.М. Расследование и предотвращение аварий на угольных шахтах. Часть 1 / А.М. Брюханов, В.И Бережинский, К.К. Бусыгин, В.П. Колосюк [и др.]. - Донецк: Донбасс, 2004. - 548 с.

4. Щевцов, В.Р. Взрывозащита горных выработок при их строительстве: Учебное пособие / В.Р. Щевцов. - Донецк: Новый мир, 1998. - 329 c.

5. Агеев, В.Г. Научные основы создания способов и средств локализации ударных волн при ведении горноспасательных работ по изоляции пожаров / Диссертация на соискание доктора технических наук. - специальность: Пожарная и промышленная безопасность. - Донецк: ГНИИГД «Респиратор», 2016. - 417 с.

6. Минеев, С.П. Способы прогноза и борьбы с газодинамическими явлениями на шахтах Украины / С.П. Минеев. - Мариуполь: Восточный издательский дом, 2016. - 286 с.

7. Бабокин, И.А. Профилактика и ликвидация аварий в угольных шахтах / И.А. Бабокин. // Уголь. - 1996. - № 9. - С. 53-55.

8. Опарин, В.Н. Аналитический обзор взрывов метана в шахтах Кузбасса / В.Н. Опарин, В.А. Скрицкий // Уголь. - 2012. - № 2. - C. 29-32.

9. Костарев, А.П. О предупреждении взрывов метана и пыли и снижении взрывоопасности шахт / А.П. Костарев // Уголь. 2002. - № 1. - С. 57-62.

10. Сластунов, С.В. Обоснование выбора и эфффективная реализация способов дегазации при интенсивной отработке газоносных угольных пластов - ключевой вопрос обеспечения метанобезопасности угольных шахт / С.В. Сластунов, Г.П. Ермак // Уголь. - 2013. - № 1. - С. 21-24.

11. Носенко, В.Д. Как ликвидировать взрывы метана на шахтах / В.Д. Носенко, Ю.Л. Худин // Уголь. - 2012. - № 2. - С. 33-36.

12. Грядущий, Б.А. Об аварии, произошедшей на шахте «Степова» / Б.А. Грядущий, С.П. Минеев, И.А. Ященко, А.И. Холод, И.Б. Беликов // Уголь Украины. - 2017, № 7,8. - С.48-53.

13. Рубан, А.Д. Подготовка и разработка высокогазоносных угольных пластов: Справочное пособие / А.Д. Рубан, В.Б. Артемьев, В.С. Забурдяев, В.Н. Захаров [и др.]. - М.: Горная книга, 2010. - 500 с.

14. Колесниченко, Е.А. Причины и возможные методы предотвращения взрывов метана и пожаров в шахтах России // Е.А. Колесниченко, И.Е. Колесниченко // Горная промышленность. - 2004. - № 1.

15. Булат, А.Ф. Управление аэрологическими и геомеханическими процессами в угольных шахтах // А.Ф. Булат, К.К. Софрийский, Б.В. Бокий, А.В. Шейко [и др.]. - Мариуполь: Східний видавничий дім, 2016. - 300 с.

16. Минеев, С.П. Горные работы в сложных условиях на выбросоопасных пластах / С.П. Минеев, А.А. Рубинский, О.П. Витушко, А.Г. Радченко. - Донецк: Східний видавничий дім, 2010. - 604 с.

17. Мясников, А.А. Предупреждение взрывов газа и пыли в угольных шахтах / А.А. Мясников, С.П. Старков, В.И. Чикунов. М.: Недра, 1985. - 205 с.

18. КД 12.01.401-96 Эндогенные пожары на угольных шахтах Донбасса. Предупреждение и тушение. Инструкция. Издание официальное / П.С. Пашковский, В.К. Костенко, В.П. Заславский, А.Т. Хорольский, А.Г. Заболотный [и др.]. - Донецк: НИИГД, 1997. $-68 \mathrm{c}$.

19. Минеев, С.П. Оценка импульсного метановыделения в зонах геологических нарушений при обрушении кровли / С.П. Минеев, В.Н. Кочерга, А.С. Янжула // Уголь Украины. - 2016. - № 1. - С. 11-18.

20. Агафонов, А.В. Условия образования метана на сопряжениях лав с вентиляционными выработками / А.В. Агафонов, А.И. Бобров, Е.П. Захаров, И.Н. Попов // Уголь Украины. - 2004. - № 7. - С. 30-31.

21. УН, Л. О результатах расследования аварий на шахтах Кузбасса, отрабатывающих склонные к самовозгоранию пласты / Л.Х. Ун, П.А. Шлапоков, А.И. Кравченко, А.В. Лебедев // Вестник: Научно-технический журнал. - 2013. - № 2. - С. 20-25.

22. Минеев, С.П. Активация десорбции метана в угольных пластах / С.П. Минеев, А.А. Прусова, М.Г. Корнилов. - Днепропетровск: Вебер, 2007. - $250 \mathrm{c}$.

23. Mineev, S. Application of shock blasting mode in mine roadway construction / S. Mineev, O. Yanzhula, O. Yulai, O. Miniev, V. Zabolotnirova // Journal «Mining of Mineral Deposits». - National mining university, 2016. - Vol. 10, Issue 2. - P. 91-96. 
24. Мінєєв, С.П. Використання режиму струсного підривання при проведенні виробок / С.П. Минеев, А.С. Янжула, М.А. Кишкань, О.С. Мінєєєв // Геотехническая механика: Межвед. сб. науч. тр. - Днепропетровск, 2016. - Вып. 129. - С. 173-180.

\section{REFERENCES}

1. Mineev, S.P. (2017), "Enemy or friend, mine methane, we decide for ourselves", Ohorona pratci: Dodatok do zhurnalu [Labor Protection: Application of the journal], no. 12, pp. 49-53, Kyiv, Ukraine.

2. Mineev, S.P. (2018), "On the prevention of accidents associated with explosions of methane in coal mines", Ugol Ukrainy [Coal of Ukraine], no. 1-2. - pp. 50-59, Kyiv, Ukraine.

3. Bryukhanov, A.M. and Berezhinskiy, V.I. (et al.) (2004), Rassledovaniye i predotvrashcheniye avariy na ugol'nykh shakhtakh. Chast 1 [Investigation and prevention of accidents at coal mines. Part 1], NORD-PRESS, Donetsk, Ukraine.

4. Shchevtcov, V.R. (1998), Vzryvozashchita gornykh vyrabotok pri ikh stroitelstve: Uchebnoye posobiye [Explosion protection of mine workings during their construction: Textbook], Novyi mir, Donetsk, Ukraine.

5. Ageev, V.G. (2016), "Scientific foundations for the development of methods and means for localizing shock waves when conducting mine rescue work to isolate fires", D. Sc. Thesis, Fire and industrial safety, State Research Institute of Mine Rescue. - Donetsk, Ukraine.

6. Mineyev, S.P. (2016), Sposoby prognoza i borby s gazodinamicheskimi yavleniyami na shakhtakh Ukrainy [Methods for forecasting and control of gas-dynamic phenomena in mines Ukraine], Vostochnyy izdatelskiy dom, Mariupol, Ukraine.

7. Babokin, I.A. (1996), "Prevention and elimination of accidents in coal mines", Coal, no. 9, pp. 53-55.

8. Oparin, V.N. and Skritskiy, V.A. (2012), "Analytical review of methane explosions in the mines of Kuzbass", Coal, no. 2, pp. 2932.

9. Kostarev, A.P. (2002), "On prevention of methane explosions and dust and reduction of explosion hazard of mines", Coal, no. 1, pp. 57-62.

10. Slastunov, S.V. and Yermak, G.P. (2013), "Justification of the choice and effective implementation of degassing methods for intensive mining of gas-bearing coal seams - a key issue in ensuring the methane safety of coal mines", Coal, no. 1, pp. 21-24.

11. Nosenko, V.D. and Khudin, Yu.L. (2012), "How to eliminate methane explosions in mines", Coal, no. 2, pp. 33-36.

12. Griadushchyi, B.A., Mineev, S.P., Yashchenko, I.A., Holod, A.I. and Belikov, I.B. (2017), "About the accident that occurred at the Stepova mine", Coal of Ukraine, no. 7,8. pp. 48-53.

13. Ruban, A.D., Artemyev, V.B. (et al.) (2010), Podgotovka i razrabotka vysokogazonosnykh ugolnykh plastov [Preparation and development of high-gas-bearing coal seams], Gornaya kniga, Moscow, Russia.

14. Kolesnichenko, Ye.A. and Kolesnichenko, I.Ye. (2004), "The causes and possible methods of preventing methane and fire explosions in the mines of Russia", Gornaya promyshlennost, no. 1.

15. Bulat, A.F., Sofiyskiy, K.K. (et al.) (2016), Upravleniye aerologicheskimi i geomekhanicheskimi protsessami v ugolnykh shakhtakh [Management of aerological and geomechanical processes in coal mines], Skhidniy vidavnichiy dim, Mariupol, Ukraine.

16. Mineev, S.P., Rubinskiy, A.A. (et al.) (2010), Gornyye raboty v slozhnykh usloviyakh na vybrosoopasnykh plastakh [Mining in difficult conditions on the outburst hazardous layers], Skhidniy vidavnichiy dim, Donetsk, Ukraine.

17. Myasnikov, A.A., Starkov, S.P. and Chikunov, V.I. (1985), Preduprezhdeniye vzryvov gaza i pyli v ugolnykh shakhtakh [Prevention of gas explosions and dust in coal mines], Nedra, Moscow, USSR.

18. Pashkovskiy, P.S., Kostenko, V.K. (et al.) (1997), KD 12.01.401-96 Endogennyye pozhary na ugolnykh shakhtakh Donbassa. Preduprezhdeniye i tusheniye. Instruktsiya. Izdaniye ofitsialnoye [KD 12.01.401-96 Endogenous fires in the coal mines of Donbass. Prevention and suppression. Instructions. Official publication], State Research Institute of Mine Rescue, Donetsk, Ukraine.

19. Mineev, S.P., Kocherga, V.N. and Yanzhula, A.S. (2016), "Estimation of impulse methane evolution in zones of geological disturbances during roof collapse", Ugol Ukrainy, no. 1, pp. 11-18.

20. Agafonov, A.V., Bobrov, A.I. (et al.) (2004), "The conditions for the formation of methane on conjugations of lavas with ventilations", Ugol Ukrainy, no. 7, pp. 30-31.

21. Un, L.Kh., Shlapokov, P.A. (et al.) (2013), "On the results of the investigation of accidents in the mines Kuzbass executed by spontaneously combustible layers", Vestnik, no. 2, pp. 20-25.

22. Mineev, S.P., Prusova, A.A. and Kornilov, M.G. (2007), Aktivatsiya desorbtsii metana v ugolnykh plastakh [Activation of methane desorption in coal seams], Veber, Dnipropetrovsk, Ukraine.

23. Mineev, S., Yanzhula, O. (et al.) (2016), "Application of shock blasting mode in mine roadway construction", Mining of Mineral Deposits, vol. 10, issue 2, pp. 91-96.

24. Mineev, S.P., Yanzhula, A.S. (et al.) (2016), "Using the shake blasting during excavation”, Geo-Technical Mechanics, vol. 129, pp. 173-180.

\section{Об авторе}

Минеев Сергей Павлович, доктор технических наук, профессор, заведующий отделом, Институт геотехнической механики им. Н.С. Полякова НАН Украины, Днепр, Украина, sergmineev@gmail.com

\section{About the author}

Mineyev Sergey Pavlovich, Doctor of Technical Sciences (D. Sc.), Professor, Head of the department, Institute of Geotechnical Mechanics named by N. Polyakov of National Academy of Science of Ukraine (IGTM NASU), Dnipro, Ukraine, sergmineev@gmail.com

Анотація. Розглянуто основні питання попередження шахтних аварій, які пов'язані з вибухами метано-повітряної суміші при веденні гірських робіт. Розглянуто сутність питання підвищеної вибухо-, газо- і пиленебезпеки при 
веденні гірських робіт в умовах шахт. В даній статті проведено аналіз вибухоаварійності на шахтах і розглянуті основні причини, що призводять до вибуху в шахті. Розглядаючи ці основні причини та фактори, виділені наступні: порушення режиму провітрювання через перерозподіл повітря між виробками; зміни режиму роботи видобувних машин і організації робіт в бік прискорення, а також істотні зміни гірничо-геологічних умов. При розтині забоєм вироблення геологічного порушення, зони розвантаження пласта, усть дегазаційних, розвідувальних та інших технічних свердловин без прийняття відповідних заходів щодо поліпшення провітрювання досить часто мають місце загазування, причому нерідко імпульсного характеру.

Незадовільне управління покрівлею і проведення непланових часто непотрібних виробок з подальшою їх ізоляцією без погашення, а також порушення провітрювання тупикових вибоїв в результаті зупинки вентилятора місцевого провітрювання, розриву вентиляційних труб, стискання і несвоєчасного їх нарощування в призабойному просторі.

До основних факторів, що стимулюють реалізацію вибухів метану, також відносяться раптові викиди вугілля і газу, суфрлярні і імпульсні виділення метану. Крім того, до причин вибухів можна віднести неправильне розгазування раніше заперемичених виробок при ізоляції пожежо- або вибухонебезпечної ділянки, планові зупинки головних і допоміжних вентиляторів в результаті ревізії, ремонту, демонтажу і перенесення обладнання, реверсу повітряного струменя, інженерні помилки в розрахунках, замірах повітря, застосування недосконалих схем розтину, підготовки і відпрацювання пластів, систем розробки, незадовільний контроль за провітрюванням гірничих виробок, а також не коректно працює газовимірювальна апаратура і інші фрактори.

Виконано аналіз причин і факторів скупчення метану, класифікація їх в окремі групи, показане їх різноманіття, звернуто увагу на поєднання несприятливих чинників, недооцінку пилогазової обстановки в процесі ведення гірських робіт.

Ключові слова: аварія, вибухи метану, пожежа, аерогазовий контроль, вугільна шахта.

Abstract. Main issues on preventing mine accidents, which are associated with explosions of methane-air mixtures during mining operations, are considered. Essence of the problem of high risk of explosion and gas-and-dust hazard during mining operations in mines is considered. In this article, explosion hazard in mines is analyzed, and key causes and factors leading to explosion in the mine are considered, among which are the following: violation of ventilation regime due to the redistribution of air between the roadways; changed operating mode and work pace of mining machines, as well as significant changes in mining and geological conditions. When roadway with geological disturbance, zone of stratum unloading, mouths of degassing, exploratory and other technical wells are opened by the face without undertaking appropriate measures for improving ventilation, then their gassing, including of impulsive character, often happens.

The main factors that provoke methane explosions also include sudden coal and gas outbursts and methane blowers and impulse emissions. Besides, key reasons of the explosions include improper degassing of roadways previously stopped for isolating area with fire or explosion risk; scheduled stoppage of main and auxiliary fans as a result of revision, repair, dismantling and relocation of equipment; reverse air jet; engineering errors in calculations and air measurements; application of imperfect schemes of opening, preparation and development of seams and development systems; unsatisfactory control over ventilation in the mine roadways, as well as disfunction of gas measuring equipment, and other factors.

Causes and factors of methane accumulation were analyzed and classified into groups with description of their diversity; special attention was focused on combination of unfavorable factors and underestimation of the dust and gas factors in the process of mining.

Keywords: accident, methane explosions, fire, air-gas monitoring, coal mine.

Статья поступила в редакцию 08.02.2018

Рекомендовано к печати д-ром техн. наук В.Г. Шевченко 